\title{
Olfactory Bulb Signal Abnormality in Patients with COVID-19 Who Present with Neurologic Symptoms
}

\author{
(D) S.B. Strauss, (D).E. Lantos, (D) L.A. Heier, DD.R. Shatzkes, and (D) C.D. Phillips
}

\begin{abstract}
BACKGROUND AND PURPOSE: Unique among the acute neurologic manifestations of Severe Acute Respiratory Syndrome coronavirus 2, the virus responsible for the coronavirus disease 2019 (COVID-19) pandemic, is chemosensory dysfunction (anosmia or dysgeusia), which can be seen in patients who are otherwise oligosymptomatic or even asymptomatic. The purpose of this study was to determine if there is imaging evidence of olfactory apparatus pathology in patients with COVID-19 and neurologic symptoms.
\end{abstract}

MATERIALS AND METHODS: A retrospective case-control study compared the olfactory bulb and olfactory tract signal intensity on thin-section T2WI and postcontrast 3D T2 FLAIR images in patients with COVID-19 and neurologic symptoms, and age-matched controls imaged for olfactory dysfunction.

RESULTS: There was a significant difference in normalized olfactory bulb T2 FLAIR signal intensity between the patients with COVID-19 and the controls with anosmia $(P=.003)$. Four of 12 patients with COVID-19 demonstrated intraneural T2 signal hyperintensity on postcontrast 3D T2 FLAIR compared with none of the 12 patients among the controls with anosmia $(P=.028)$.

CONCLUSIONS: Olfactory bulb 3D T2 FLAIR signal intensity was greater in the patients with COVID-19 and neurologic symptoms compared with an age-matched control group with olfactory dysfunction, and this was qualitatively apparent in 4 of 12 patients with COVID-19. Analysis of these preliminary finding suggests that olfactory apparatus vulnerability to COVID-19 might be supported on conventional neuroimaging and may serve as a noninvasive biomarker of infection.

ABBREVIATIONS: COVID-19 = coronavirus disease 2019; OB = olfactory bulb; SARS-CoV-2 = Severe Acute Respiratory Syndrome coronavirus 2

$\mathbf{S}$ evere Acute Respiratory Syndrome coronavirus 2 (SARS$\mathrm{CoV}-2)$, the virus responsible for the coronavirus disease 2019 (COVID-19) pandemic, may produce a broad range of acute neurologic symptoms that involve both the CNS and the peripheral nervous system, including stroke, ${ }^{1}$ meningitis, encephalitis, Guillain-Barré syndrome, and acute necrotizing hemorrhagic encephalopathy. ${ }^{2}$ Unique among these acute neurologic manifestations is chemosensory dysfunction (anosmia or dysgeusia), which can be seen in patients who are otherwise oligosymptomatic or even asymptomatic. A single-institution report from the United States that involved 1480 patients with COVID-19

Received May 26, 2020; accepted after revision June 30.

From the Department of Radiology (S.B.S., J.E.L., L.A.H., C.D.P.), Weill Cornell Medical College, New York-Presbyterian, New York, New York; and Department of Radiology (D.R.S.), Zucker School of Medicine at Hofstra/Northwell, Lenox Hill Hospital and The New York Head and Neck Institute, New York, New York.

Please address correspondence to C. Douglas Phillips, MD, Weill Cornell Imaging at New York-Presbyterian, 1305, York Ave 3rd Floor, New York, NY 10021; e-mail: cdp2001@med.cornell.edu; @CDP_Rad

- Indicates open access to non-subscribers at www.ajnr.org

http://dx.doi.org/10.3174/ajnr.A6751 testing showed that loss of smell and taste was reported in $68 \%$ of patients who tested positive for COVID 19, of whom, $26 \% \mathrm{did}$ not recover. ${ }^{3}$ The reported incidence of anosmia varies internationally: as low as $30 \%$ in South Korea, where there is widespread testing, and as high as $88 \%$ in Europe, where testing practices might be less uniform. ${ }^{4-11}$ Chemosensory symptoms may present as viral prodromes or be concomitant with the development of other disease symptoms. ${ }^{12}$ Although olfactory dysfunction can be seen with rhinoviruses, parainfluenza, Epstein-Barr virus, and other coronaviruses, this symptom is typically linked with rhinorrhea and nasal obstruction, whereas there is accumulating evidence that SARS-CoV-2 associated olfactory dysfunction is seen independent of nasal congestion. ${ }^{2,6}$ Anosmia in the absence of other symptoms is reported in as many as 1 of 6 individuals with SARS-CoV-2 infection. ${ }^{10}$

The olfactory bulbs (OBs) are easily identified on conventional MR imaging and are located immediately beneath the olfactory sulci within the anterior cranial fossa, above the cribriform plate. The normal imaging appearance of the adult $\mathrm{OB}$ is well described ${ }^{13-15}$ and should appear oval- or j-shaped in morphology and demonstrate uniform T2 signal intensity from the center to 
the periphery. ${ }^{15}$ The olfactory neural network includes first-order projections to the piriform cortex and amygdala as well as secondary projections, including the orbitofrontal cortex, thalamus, and insula. ${ }^{16}$ Morphologic changes in the $\mathrm{OB}$ and associated areas have been shown in various other disease states, including chronic rhinosinusitis, post-viral anosmia, and neurodegenerative disease. ${ }^{17-19}$ Moreover, both central and peripheral components of the olfactory system seem to have distinct functional roles in olfactory perception. ${ }^{20}$

Although much remains unknown with regard to the pathophysiology of anosmia in the setting of COVID-19, given that chemosensory dysfunction is reported as the first symptom of disease in up to $27 \%$ of patients, ${ }^{21}$ imaging-detected $\mathrm{OB}$ pathology might serve as a noninvasive biomarker for infection. To our knowledge, there are no studies that systematically evaluated patients with COVID-19 for radiologic evidence of OB, tract, and olfactory association area abnormalities. The purpose of this study was to determine if there is imaging evidence of olfactory apparatus pathology in patients with COVID-19 and neurologic symptoms. We hypothesize that individuals with COVID-19 will show evidence of $\mathrm{OB}$ pathology manifesting as OB signal abnormality.

\section{MATERIALS AND METHODS Subject Enrollment}

This was a Health Insurance Portability and Accountability Act retrospective, case-control study performed with approval of the institutional review board at Weill Cornell Medical Center. A radiology report data base query was performed to identify all patients with suspected or confirmed COVID-19 and MR imaging of the brain performed as part of standard of care between April 4, 2020, and May 4, 2020. Inclusion criteria for subjects included positive SARS-CoV-2 reverse transcription-polymerase chain reaction result from nasopharyngeal specimen, MR imaging examination, including thin-section coronal T2WI of the OB $(2 \mathrm{~mm})$ and high-resolution 3D T2 FLAIR images of the whole brain. An age-matched control group was scanned for olfactory dysfunction with previous MR imaging of the brain that included thin-section coronal T2WI and high-resolution 3D T2 FLAIR.

\section{Imaging Acquisition}

MR images were acquired by using a 3T MR imaging system on several in- and outpatient scanners at our institution: Signa Architect (GE Healthcare; 6 cases, 3 controls), Discovery 750W (GE Healthcare; 6 cases), Skyra (Siemens; 9 controls) by using a 48-channel head coil. Coronal T2WIs of the OB were acquired with the following parameters: repetition time/echo time, 2744.0/ $108.3 \mathrm{~ms}$; field of view, $180.0 \times 180.0 \mathrm{~mm}$; and section thickness, $2.0 \mathrm{~mm}$. Sagittal 3D T2 FLAIR images were acquired after the administration of Gadavist (gadobutrol) $0.1 \mathrm{mmol} / \mathrm{kg}$ (Bayer Schering Pharma) intravenous contrast with the following parameters: repetition time/echo time $6002.0 / 126.9 \mathrm{~ms}$; inversion time, $1681.0 \mathrm{~ms}$; field of view, $215.3 \times 108.7 \mathrm{~mm}$; and section thickness, $1.0 \mathrm{~mm}$ (with 3-mm coronal and axial reconstructed images).

\section{Imaging Data Analysis}

Evaluation of the patients and the controls was done via consensus review by 2 neuroradiologists (L.A.H. [with 34 years of imaging experience], J.L. [with 10 years of imaging experience]); a
Table 1: Kennedy staging

\begin{tabular}{ll}
\hline Stage & Description \\
\hline 0 & Normal \\
I & Anatomic abnormalities, unilateral sinus disease, bilateral \\
& disease limited to ethmoid sinuses \\
II & $\begin{array}{c}\text { Bilateral ethmoid disease with involvement of } 1 \\
\text { dependent sinus }\end{array}$ \\
III & $\begin{array}{c}\text { Bilateral ethmoidal disease with involvement of } 2 \text { or } \\
\text { more dependent sinuses on each side }\end{array}$ \\
IV & Diffuse sinonasal polyposis \\
\hline
\end{tabular}

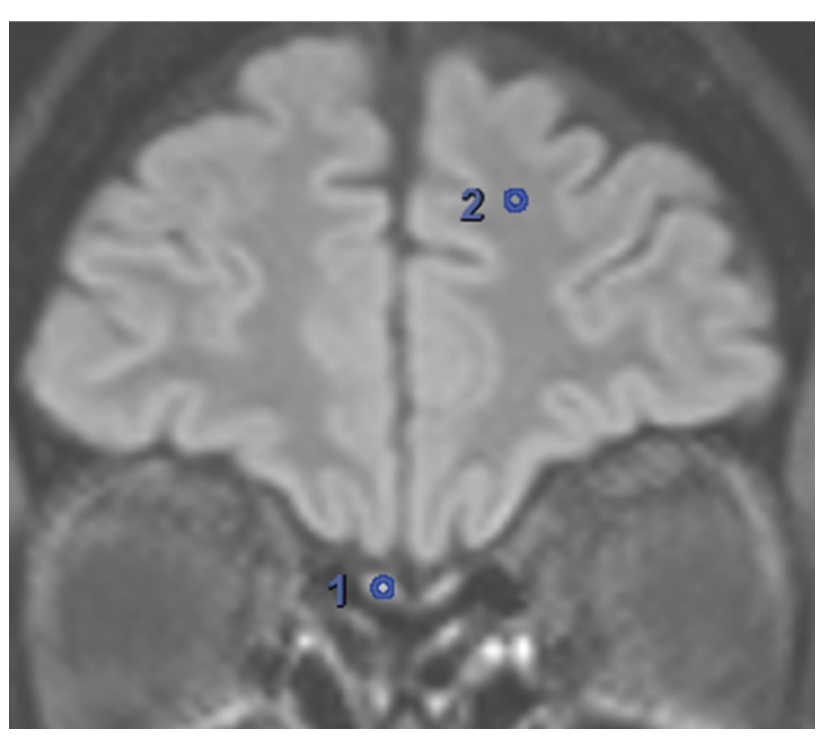

FIG 1. Quantitative assessment of $O B$ signal intensity. For each patient, the ROI is drawn at the mid segment of the $O B$ and within the left superior frontal WM to calculate normalized values.

third neuroradiologist (C.D.P. [with 30 years of imaging experience]) adjudicated the differences when consensus was not reached. All the reviewers were blinded to patient category. Consensus review was performed for the following measures: Kennedy staging for paranasal sinus disease (0-IV), mucosal disease that involves the olfactory recess, loss of $\mathrm{OB}$ volume (coronal $\mathrm{T} 2$ of the $\mathrm{OB}$ ), $\mathrm{OB}$ and olfactory tract signal abnormality (coronal $\mathrm{T} 2$ of the $\mathrm{OB}$ ), $\mathrm{OB}$ and olfactory tract signal abnormality (3D T2 FLAIR), the presence of abnormality in the piriform cortex and amygdala, the presence of signal abnormality in the orbitofrontal cortex, and evaluation for other relevant imaging findings (the presence of acute stroke; chronic microvascular disease graded as mild, moderate, severe). Paranasal sinus disease was assessed by using the Kennedy staging, ${ }^{22}$ as outlined in Table 1 . The OB volume loss was a qualitative determination based on loss of the normal oval- or J-shaped morphology, or loss of volume compared with the contralateral $\mathrm{OB} .{ }^{15}$ The $\mathrm{OB}$ and olfactory tract signal intensity was assessed relative to the trigeminal nerve; $\mathrm{OB}$ and olfactory tract hyperintense to the trigeminal nerve was classified as abnormal. Quantitative assessment of the OB signal intensity was also performed. For each patient, an ROI was drawn at the mid segment of the $\mathrm{OB}$ as well as in the left superior frontal WM to calculate normalized values (Fig 1).

Patients were excluded if coronal T2WI of the OB was not performed $(n=19)$, high-resolution 3D T2 FLAIR was not 
Table 2: Demographic and clinical characteristics of patients and controls

\begin{tabular}{|c|c|c|}
\hline Characteristic & Patients $(n=12)$ & Controls $(n=12)$ \\
\hline $\begin{array}{l}\text { Age, mean } \pm \text { standard } \\
\text { deviation, } y\end{array}$ & $58.25 \pm 14.852$ & $58.00 \pm 13.824$ \\
\hline Sex at birth & 6 women, 6 men & 9 women, 3 men \\
\hline $\begin{array}{l}\text { Indication for study } \\
\qquad(n / N)\end{array}$ & $\begin{array}{l}\text { Altered mental status }(9 / 12) \text {; } \\
\text { ataxia, dysarthria }(1 / 12) ; \text { status } \\
\text { epilepticus }(1 / 12) \text {; paresthesia, } \\
\text { anosmia }(1 / 12)\end{array}$ & $\begin{array}{l}\text { Anosmia (7); phantosmia (2); } \\
\text { hyposmia (3) }\end{array}$ \\
\hline \multicolumn{3}{|l|}{$\begin{array}{c}\text { Kennedy staging } \\
\text { score, } n / N\end{array}$} \\
\hline 0 & 3 & 7 \\
\hline I & 4 & 2 \\
\hline II & 0 & 0 \\
\hline III & 2 & 0 \\
\hline IV & 3 & 3 \\
\hline $\begin{array}{l}\text { Olfactory recess } \\
\text { involvement, } n / N\end{array}$ & 0 & 1 \\
\hline
\end{tabular}

psychiatric symptoms in the absence of pulmonary manifestations of the infection. Among the 11 patients with COVID-19 who presented and required hospitalization, the length of stay ranged from 4 to 71 days (mean, 27 days). Seven of 12 patients with COVID-19 received hydroxychloroquine over the course of their treatment.

There was a significant difference in a normalized OB T2 FLAIR signal intensity between the patients with COVID-19 (mean normalized signal intensity, 1.85 [range, 0.74-1.85]) and the controls with anosmia (mean normalized signal intensity, 1.27 [range, performed $(n=10)$, if motion degradation precluded satisfactory evaluation $(n=1)$, or if the final SARS-CoV-2 reverse transcription-polymerase chain reaction result was negative $(n=3)$. One patient underwent 2 examinations; therefore, only the first study was included. The remaining 12 patients with a history of COVID-19 infection and sequences of interest were included in the study. Demographic data (age, sex at birth), date of positive SARS-CoV-2 reverse transcription-polymerase chain reaction result, and date of examination were recorded. A total of 12 agematched controls who underwent MR imaging of the brain with an olfactory protocol were also included.

\section{Statistical Analyses}

Statistical analyses were performed by using SPSS (version 26; IBM). The $\chi^{2}$ test of independence was used to assess significant differences between patients with COVID-19 and the anosmia control group in OB T2 FLAIR hyperintensity. The independent 2-sample $t$ test was performed to test for significance of difference in age and the Kennedy staging score between patients with COVID-19 and the controls with anosmia, and normalized OB T2 FLAIR signal intensity between patients with COVID-19 and the controls with anosmia. The Spearman rank correlation analysis was used to test for significance of association between age and normalized OB T2 FLAIR signal intensity.

\section{RESULTS}

Demographic and clinical characteristics of the patients and the controls are shown in Table 2. There was no significant difference in age between the 2 groups $(P=.966)$. There were significantly more women in the anosmia control group ( 9 women, 3 men) compared with patients with COVID-19 (6 women, 6 men) $(P<.001)$. All the subjects included within the COVID-19 group had laboratory confirmation of SARS-Cov-2 infection. The average latency between the COVID-19 diagnosis and the MR imaging examination was 14.17 days (range, 0-32 days). There was no significant difference between the patients with COVID-19 and the controls with anosmia, and the grading of paranasal sinus mucosal disease $(P=.346)$. There was a range of disease severity among the patients with COVID-19: five patients required intubation and 5 patients presented with purely neurologic and/or
0.99-3.13]) ( $P=.003$ ) (Fig 2). There was no correlation between age and a normalized $\mathrm{OB}$ signal intensity $(R=-0.128, P=.552)$. The patients with COVID-19 and the controls with anosmia did not demonstrate $\mathrm{OB}$ volume loss or signal abnormality based on thin-section T2WI of the OB. However, 4 of 12 patients with COVID-19 demonstrated intraneural T2 signal hyperintensity on 3D T2 FLAIR (Figs 3 and 4) compared with none of the 12 patients (Fig 5) among the controls with anosmia $(P=.028)$. Of the patients in the COVID-19 group, there was no significant difference between those with and those without $\mathrm{OB}$ and olfactory tract neuritis, and the number of days between the COVID19 diagnosis and the MR imaging examination $(P=.882)$ or severity of paranasal sinus disease $(P=.080)$. Olfactory recess disease was seen in a single control with anosmia but not in any of the patients with COVID-19. A single patient with COVID-19 demonstrated an increased $\mathrm{T} 2$ signal in the entorhinal cortex and the orbitofrontal cortex; this individual was admitted for delirium and lethargy in the setting of Escherichia coli urinary tract infection, with persistent altered mental status despite resolution of the infection.

In terms of additional imaging findings on the performed examinations, there was a significant difference in distribution among categories of chronic microvascular ischemic disease (none, mild, moderate, severe) between the patients and the controls, as shown in Table $3(P \leq .001)$. Additional notable findings included posterior reversible encephalopathy syndrome (2 patients with COVID-19, neither of whom demonstrated qualitatively increased $\mathrm{OB}$ and olfactory tract signal intensity on 3D T2 FLAIR) and acute infarction (2 patients with COVID-19, 1 of whom demonstrated qualitatively increased $\mathrm{OB}$ and olfactory tract signal intensity on 3D T2 FLAIR). Anosmia data were available for only 1 of the 12 patients with COVID-19. This individual presented with right arm numbness, paresthesia, and loss of sense of smell, and was found to have increased T2 signal in the OB and olfactory tract on 3D T2 FLAIR.

\section{DISCUSSION}

In this retrospective case-control study that examined imaging correlates to COVID-19, we found that the patients with acuteto-subacute COVID-19 were more likely to demonstrate 


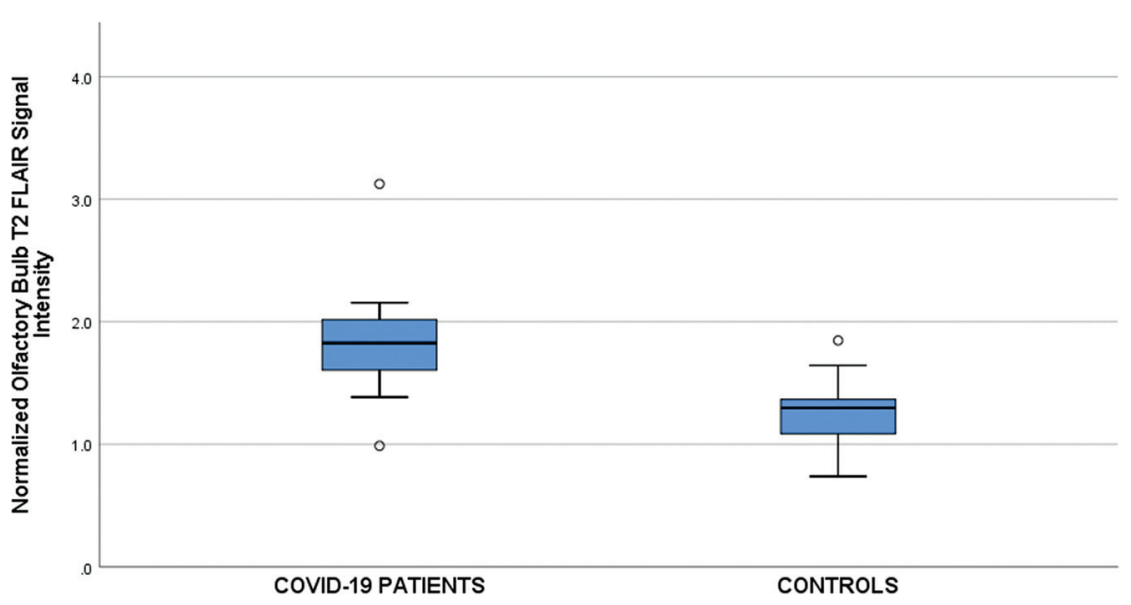

FIG 2. Normalized OB T2 FLAIR signal intensity in patients and controls. Box-and-whisker plots show median and interquartile ranges for each group. There was a significant difference in mean signal intensity between the patients and the controls $(P=.003)$. Findings remain significant even with the exclusion of the COVID-19 high outlier depicted at a mean normalized OB T2 FLAIR signal intensity of 3.1.
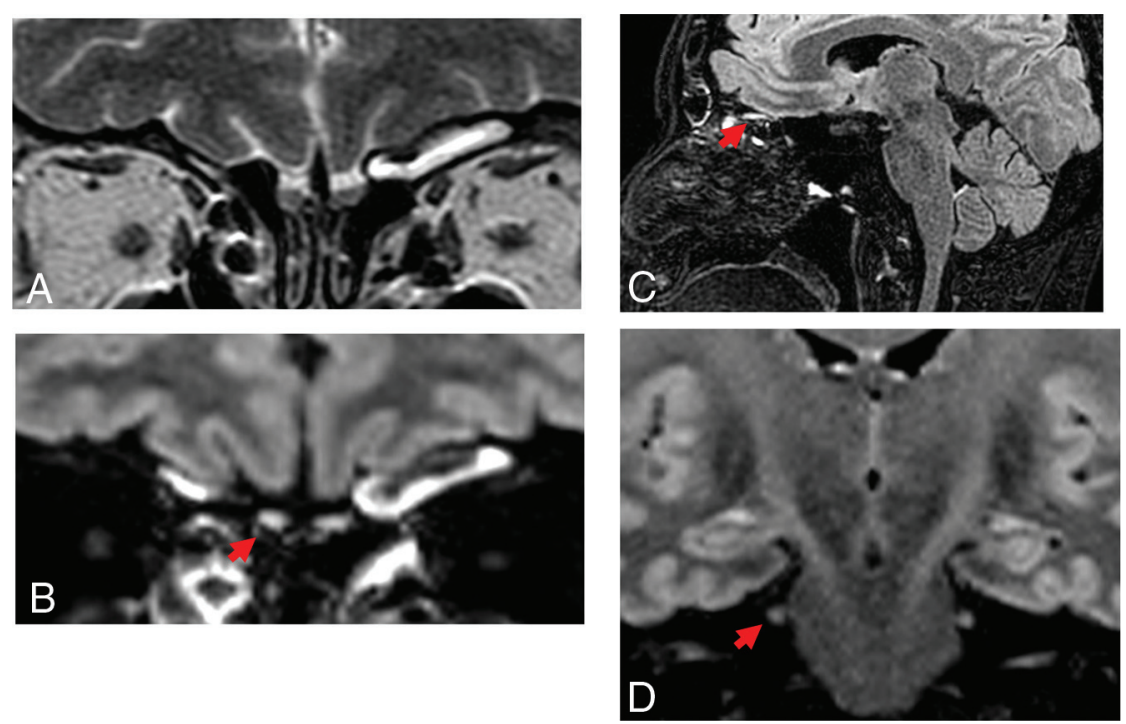

FIG 3. A 48-year-old woman positive for COVID-19 who presented with weakness and unsteady gait of 1 week's duration. Neurologic examination was significant for truncal ataxia, dysarthria, and left-sided dysmetria. A, Coronal high-resolution T2WI demonstrates normal OB morphology and signal intensity. B, Coronal and (C) sagittal postcontrast T2 FLAIR images demonstrate an increased T2 signal within the $\mathrm{OB}$ (red arrows). Note relative increased signal compared with (D) coronal T2Wl at the level of the intracisternal segment of the trigeminal nerve (red arrow).

preliminary findings have important implications in terms of establishing biomarkers for acute infection, understanding the potential neurotropism of SARS-Cov-2, and identifying a subset of patients who might require longitudinal clinical and imaging follow-up to assess for neurologic changes.

A report by Galougahi et $\mathrm{al}^{23}$ demonstrated no signal abnormality or morphologic changes in a patient with sudden-onset anosmia and positive SARS-CoV-2 polymerase chain reaction result during the acute phase of the illness. Similarly, we did not detect signal abnormality on coronal T2WI; rather, signal abnormality was detected on 3D-T2 FLAIR sequences, defined as hyperintense relative to the trigeminal nerve. An additional case report on acute onset anosmia in a patient with COVID-19 demonstrated complete olfactory cleft obstruction ${ }^{24}$; in contrast, we did not find olfactory recess disease in any of our patients with COVID-19. However, given the characteristic imaging appearance, it is possible that the previously reported case represents respiratory epithelial adenomatoid hamartoma rather than pathology related to COVID-19. ${ }^{24}$

Olfactory neuritis observed in our study might be a secondary effect of olfactory dysfunction and might reflect a phenomenon similar to post-infectious olfactory loss seen in the setting of other upper respiratory infections. Although the neuroinvasive potential of SARS-COV-2 remains to be established, direct CNS inoculation due to viral neurotropism is also plausible. The anatomy of the olfactory recess and the relationship among the nasal epithe-

increased intraneural T2 signal abnormality on 3D T2 FLAIR in the $\mathrm{OB}$ compared with the controls with anosmia and not infected, which may represent enhancement or intrinsic T2 prolongation. There was a group-wise difference in normalized T2 FLAIR signal intensity between the patients with COVID-19 and the controls with anosmia. This difference was evident in 4 of 12 patients with COVID-19 on consensus review. These findings were independent of the presence of olfactory recess or paranasal sinus disease. We did not find signal abnormality in other structures related to the olfactory apparatus, including the orbitofrontal and entorhinal (piriform and amygdala) regions. These lium, OB, and CNS allows for a natural pathway for virus spread via neuronal transport. ${ }^{25}$ Trans-synaptic transfer of virus is described in SARS-CoV ${ }^{26}$ and Middle East respiratory syndrome coronavirus, ${ }^{27}$ betacoronaviruses homologous to SARSCoV-2 and responsible for previous epidemics. Preclinical experiments in transgenic mice demonstrated that the intranasal introduction of these viruses resulted in CNS inoculation, with neuronal loss in areas of viral expression. Therefore, it has been postulated that the neuroinvasive potential of SARSCOV-2 might similarly occur via a trans-synaptic route. Angiotensin-converting enzyme 2 protein expression is present 

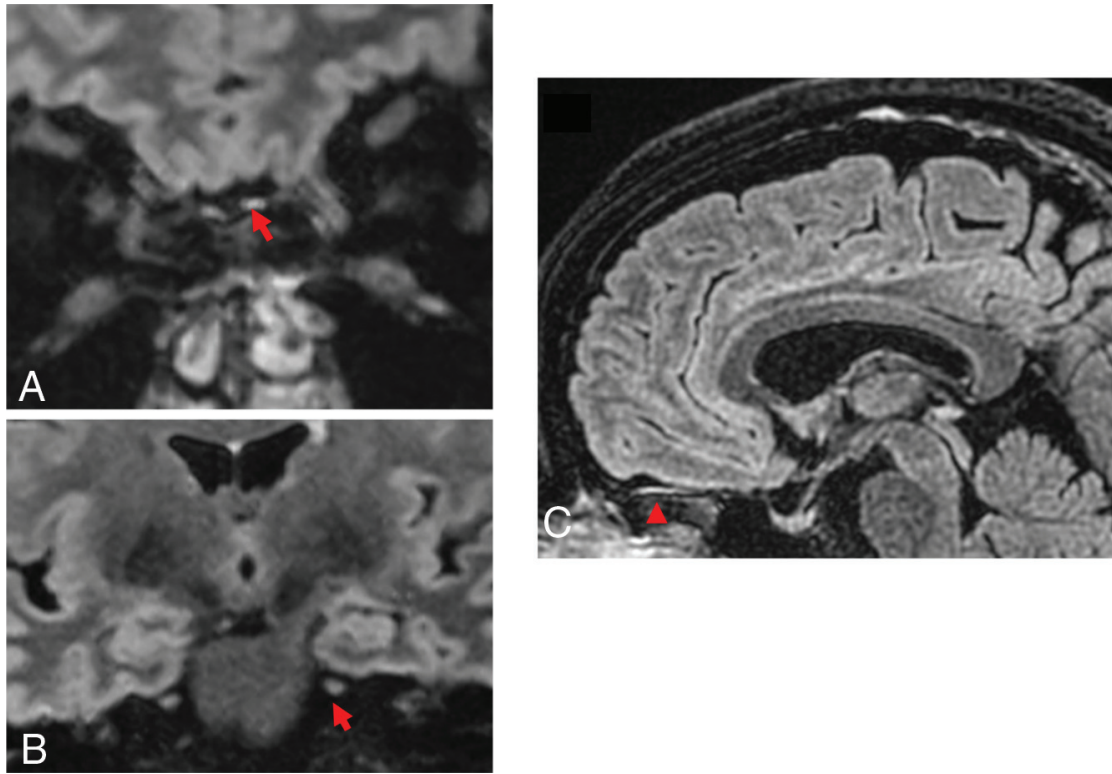

FIG 4. A 52-year-old woman positive for COVID-19 and with a history of major depressive disorder, was found to be catatonic. $A$, Coronal and $(B)$ sagittal postcontrast 3D T2 FLAIR demonstrates increased intraneural signal within the OBs (red arrows) relative to $(C)$ coronal postcontrast 3D T2 FLAIR images of the trigeminal nerve (red arrow).
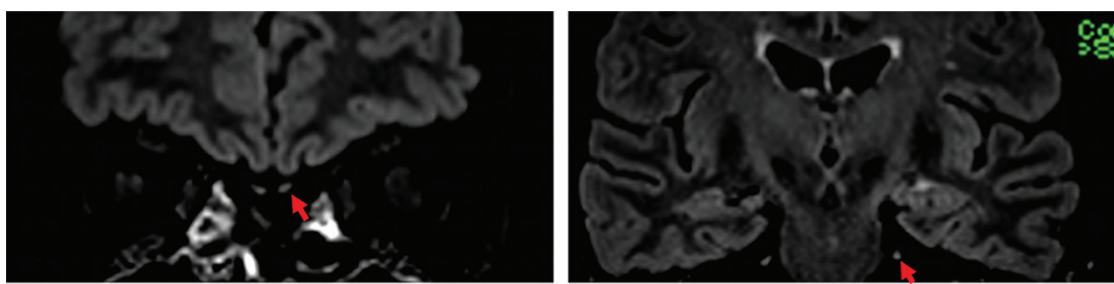

FIG 5. A 74-year-old woman (in the control group) with decreased sense of smell of several months' duration. Coronal postcontrast 3D T2 FLAIR of $(A)$ the OB (red arrow) and (B) the trigeminal nerve (red arrow) demonstrate isointense signal.

Table 3: Severity of chronic microvascular ischemic disease in patients and controls

\begin{tabular}{lllcc}
\hline \multicolumn{1}{c}{ Subjects } & None & Mild & Moderate & Severe \\
\hline Patients with COVID-19 & 0.50 & 0.25 & 0.167 & 0.83 \\
Controls with anosmia & 0.333 & 0.417 & 0.25 & 0.00 \\
\hline
\end{tabular}

in sustentacular and olfactory stem cells and may serve as a putative target for SARS-CoV-2 infection of olfactory epithelium. $^{25}$ Alternatively, viral binding to angiotensin-converting enzyme 2 receptors expressed in CNS capillary endothelium might result in endothelial damage, which enables spike protein binding to neuronal angiotensin-converting enzyme 2 receptors and subsequent CNS infection. ${ }^{28}$ Another possibility is that hematogenous spread may occur via the blood supply shared by olfactory sensory neurons and the $\mathrm{OB}$.

Imaging correlates to anosmia on conventional MR imaging have been shown in the setting of other disease status causing olfactory dysfunction. For instance, $\mathrm{OB}$ volume loss has been demonstrated in patients with migraine headache, ${ }^{29}$ chronic rhinosinusitis, ${ }^{30}$ trauma, ${ }^{30,31}$ and subsequent to upper respiratory tract infection. $^{30,32}$ Morphologic changes in the $\mathrm{OB}$ have also been demonstrated in neurodegenerative diseases, including Parkinson disease ${ }^{18}$ and Alzheimer disease. ${ }^{19}$ Chung et $\mathrm{al}^{33}$ evaluated $\mathrm{OB}$ volume and signal intensity in patients with a reported history of olfactory deficit due to chronic rhinosinusitis, trauma, prior viral infection, and idiopathic etiologies, and found that $\mathrm{OB}$ volume loss was more common in patients with olfactory dysfunction than in those with normosmia. However, there was no significant difference between the 2 groups in terms of $\mathrm{T} 2$ signal abnormality $(P=$ $.395) .^{33}$ The investigators attributed their findings to the chronicity of olfactory deficits because patients in the cohort experienced olfactory deficits for $>2$ months. ${ }^{33}$

The presence of an increased T2 signal observed in our study might reflect the acuity of the time course; it is possible that, if these individuals were imaged at longer-term follow-up, we would observe volume loss in the absence of signal abnormality. For instance, studies have demonstrated a negative correlation between the duration of anosmia and $\mathrm{OB}$ volume loss. Yao et $\mathrm{al}^{17}$ demonstrated OB volume loss in individuals with anosmia of 0.58.7 years' duration and that the volume negatively correlated with the duration of olfactory loss. In addition, Yao et $\mathrm{al}^{17}$ reported orbitofrontal cortex volume loss. In our study, a single patient with COVID-19 demonstrated increased entorhinal and orbitofrontal signal abnormality; however, the clinical significance of this isolated finding is uncertain.

There are several limitations to this study. Patients included were those who underwent MR imaging of the brain as part of standard of care during the COVID-19 pandemic. As such, our findings do not necessarily reflect patients on the milder end of the spectrum who might not have undergone imaging due to regulatory constraints or those on the more severe end of the spectrum who may have been too clinically unstable to undergo MR imaging. Although quantitative measures for the OB T2 FLAIR signal intensity were normalized to superior frontal WM, a large proportion of patients with COVID-19 underwent examinations on inpatient scanning systems versus outpatient scanning systems, and, therefore, it is possible that technical factors contributed to the differences observed between the 2 groups. Although all the patients included in the study demonstrated neurologic manifestations of disease, the presence of anosmia was not documented for all the subjects in this small-sample, retrospective study. Three of the 24 patients included in this study underwent noncontrast 3D T2 FLAIR, which might have decreased sensitivity for detection of 
signal abnormality. On consensus review, we found increased T2 signal within the OBs in $33 \%$ of patients with COVID-19, similar to some estimates of acute-onset anosmia in patients with COVID-19. ${ }^{11}$ A larger, prospective study with both self-reported and objective data ${ }^{34,35}$ on olfaction with imaging performed at uniform chronology could potentially validate these preliminary results that suggest the possibility of $\mathrm{OB}$ signal intensity as a noninvasive biomarker of disease in COVID-19.

\section{CONCLUSIONS}

OB 3D T2 FLAIR signal intensity was greater in patients with COVID-19 and neurologic symptoms compared with an agematched control group with olfactory dysfunction, and was qualitatively apparent in 4 of 12 patients with COVID-19. Analysis of these preliminary findings suggests that olfactory apparatus vulnerability to COVID-19 might be supported on conventional neuroimaging. Future prospective studies that examine the relationship between imaging findings and objective chemosensory assessment are warranted.

\section{REFERENCES}

1. Oxley TJ, Mocco J, Majidi S, et al. Large-vessel stroke as a presenting feature of Covid-19 in the young. N Engl J Med 2020;382:e60 CrossRef Medline

2. Nath A. Neurologic complications of coronavirus infections. Neurology 2020;94:809-10 CrossRef Medline

3. Wölfel R, Corman VM, Guggemos W, et al. Virological assessment of hospitalized patients with COVID-2019. Nature 2020;581:46569 CrossRef Medline

4. Bagheri SH, Asghari A, Farhadi M, et al. Coincidence of COVID-19 epidemic and olfactory dysfunction outbreak in Iran. Medical Journal of The Islamic Republic of Iran (MJIRI) 2020;34:446-52 CrossRef

5. Mao L, Jin H, Wang M, et al. Neurologic manifestations of hospitalized patients with coronavirus disease 2019 in Wuhan, China. JAMA Neurol 2020;77:1-9 CrossRef Medline

6. Lechien JR, Chiesa-Estomba CM, De Siati DR, et al. Olfactory and gustatory dysfunctions as a clinical presentation of mild-to-moderate forms of the coronavirus disease (COVID-19): a multicenter European study. Eur Arch Otorhinolaryngol 2020;277;2251-61 CrossRef Medline

7. Menni C, Valdes AM, Freidin MB, et al. Real-time tracking of selfreported symptoms to predict potential COVID-19. Nature medicine 2020;26:1037-40 CrossRef Medline

8. Gautier J-F, Ravussin Y. A new symptom of COVID-19: loss of taste and smell. Obesity (Silver Spring) 2020;28:848 CrossRef Medline

9. Yan CH, Faraji F, Prajapati DP, et al. Association of chemosensory dysfunction and Covid-19 in patients presenting with influenza-like symptoms. Int Forum Allergy Rhinol 2020;10:806-13 CrossRef Medline

10. Hopkins C, Surda P, Kumar N. Presentation of new onset anosmia during the COVID-19 pandemic. Rhinology 2020;58:295-98 CrossRef Medline

11. Giacomelli A, Pezzati L, Conti F, et al. Self-reported olfactory and taste disorders in patients with severe acute respiratory coronavirus 2 infection: a cross-sectional study. Clinical Infectious Diseases 2020;71:889-90 CrossRef Medline

12. Sedaghat AR, Gengler I, Speth MM. Olfactory dysfunction: a highly prevalent symptom of COVID-19 with public health significance. Otolaryngol Head Neck Surg 2020;163:12-15 CrossRef Medline

13. Suzuki M, Takashima T, Kadoya M, et al. MR imaging of olfactory bulbs and tracts. AJNR Am J Neuroradiol 1989;10:955-57 Medline

14. Yousem DM, Geckle RJ, Bilker WB, et al. Olfactory bulb and tract and temporal lobe volumes: normative data across decades. Ann $\mathrm{N}$ Y Acad Sci 1998;855:546-55 CrossRef Medline
15. Schneider JF, Floemer F. Maturation of the olfactory bulbs: MR imaging findings. AJNR Am J Neuroradiol 2009;30:1149-52 CrossRef Medline

16. Yousem DM, Oguz KK, Li C. Imaging of the olfactory system. Semin Ultrasound CT MR 2001;22:456-72 CrossRef Medline

17. Yao L, Yi X, Pinto JM, et al. Olfactory cortex and olfactory bulb volume alterations in patients with post-infectious olfactory loss. Brain Imaging Behav 2018;12:1355-62 CrossRef Medline

18. Wang J, You H, Liu J-F, et al. Association of olfactory bulb volume and olfactory sulcus depth with olfactory function in patients with Parkinson disease. AJNR Am J Neuroradiol 2011;32:677-81 CrossRef Medline

19. Wilson RS, Arnold SE, Schneider JA, et al. Olfactory impairment in presymptomatic Alzheimer's disease. Ann N Y Acad Sci 2009; 1170:730-35 CrossRef Medline

20. Seubert J, Freiherr J, Frasnelli J, et al. Orbitofrontal cortex and olfactory bulb volume predict distinct aspects of olfactory performance in healthy subjects. Cereb Cortex 2013;23:2448-56 CrossRef Medline

21. Kaye R, Chang CWD, Kazahaya K, et al. COVID-19 anosmia reporting tool: initial findings. Otolaryngol Head Neck Surg 2020;163:13234 CrossRef Medline

22. Lund VJ, Kennedy DW. Staging for rhinosinusitis. Otolaryngol Head Neck Surg 1997;117(pt 2):S35-40 CrossRef Medline

23. Galougahi MK, Ghorbani J, Bakhshayeshkaram M, et al. Olfactory bulb magnetic resonance imaging in SARS-CoV-2-induced anosmia: the first report. Acad Radiol 2020;27:892-93 CrossRef Medline

24. Eliezer M, Hautefort C, Hamel A-L, et al. Sudden and complete olfactory loss function as a possible symptom of COVID-19. JAMA otolaryngology-head \& neck surgery 2020;146:674-75 CrossRef Medline

25. Brann DH, Tsukahara T, Weinreb C, et al. Non-neuronal expression of SARS-CoV-2 entry genes in the olfaory system suggests mechanisms underlying COVID-19-associated anosmia. Science Advances 2020;6:eabc5801 CrossRef

26. Netland J, Meyerholz DK, Moore S, et al. Severe acute respiratory syndrome coronavirus infection causes neuronal death in the absence of encephalitis in mice transgenic for human ACE2.J Virol 2008;82:7264-75 CrossRef Medline

27. Li K, Wohlford-Lenane C, Perlman S, et al. Middle East respiratory syndrome coronavirus causes multiple organ damage and lethal disease in mice transgenic for human dipeptidyl peptidase 4 . J Infect Dis 2016;213:712-22 CrossRef Medline

28. Baig AM, Khaleeq A, Ali U, et al. Evidence of the COVID-19 virus targeting the CNS: tissue distribution, host-virus interaction, and proposed neurotropic mechanisms. ACS Chem Neurosci 2020;11: 995-98 CrossRef Medline

29. Aktürk T, Tanık N, Serin HI, et al. Olfactory bulb atrophy in migraine patients. Neurol Sci 2019;40:127-32 CrossRef Medline

30. Hummel T, Urbig A, Huart C, et al. Volume of olfactory bulb and depth of olfactory sulcus in $\mathbf{3 7 8}$ consecutive patients with olfactory loss. J Neurol 2015;262:1046-51 CrossRef Medline

31. Yousem DM, Geckle RJ, Bilker WB, et al. Posttraumatic smell loss: relationship of psychophysical tests and volumes of the olfactory bulbs and tracts and the temporal lobes. Acad Radiol 1999;6:264-72 CrossRef

32. Rombaux P, Mouraux A, Bertrand B, et al. Olfactory function and olfactory bulb volume in patients with postinfectious olfactory loss. Laryngoscope 2006;116:436-39 CrossRef Medline

33. Chung MS, Choi WR, Jeong H-Y, et al. MR imaging-based evaluations of olfactory bulb atrophy in patients with olfactory dysfunction. AJNR Am J Neuroradiol 2018;39:532-37 CrossRef Medline

34. Hummel T, Sekinger B, Wolf SR, et al. 'Sniffin'sticks': olfactory performance assessed by the combined testing of odor identification, odor discrimination and olfactory threshold. Chem Senses 1997;22: 39-52 CrossRef Medline

35. Doty RL, Shaman P, Kimmelman CP, et al. University of Pennsylvania Smell Identification Test: a rapid quantitative olfactory function test for the clinic. Laryngoscope 1984;94(pt 1):176-78 CrossRef Medline 